\title{
Estudantes universitários: a influência das variáveis socioeconômicas e culturais na carreira
}

\author{
Melina Del'Arco de Oliveira \\ Lucy Leal Melo-Silva
}

\begin{abstract}
Resumo
Este estudo descreve o perfil de concluintes dos cursos de graduação Química, Ciências Biológicas e Psicologia de uma universidade pública e busca compreender influências das variáveis sociodemográficas e acadêmicas em suas trajetórias de carreira. Os 140 participantes responderam a um questionário com variáveis sociodemográficas: escolaridade dos pais, renda familiar, nível socioeconômico e procedência do Ensino Fundamental e Médio (público ou particular). As variáveis acadêmicas (notas) foram obtidas nos prontuários arquivados na seção de Graduação. As informações sobre as trajetórias de carreira (estudo de caso) foram obtidas por meio de entrevistas com seis participantes. Os dados foram analisados quantitativamente, segundo modelo univariado - Testes do Qui-Quadrado, Não-Paramétrico Kruskal-Wallis e de Mann-Whitney, e qualitativamente, segundo Bardin (1977). Referenciais teóricos nacionais e internacionais subsidiaram as discussões. Verificou-se que a escolaridade dos pais, nível socioeconômico e natureza do ensino cursado estão proporcionalmente relacionados ao sucesso no vestibular e à escolha da carreira.
\end{abstract}

Palavras-chave: Estudantes universitários, desenvolvimento profissional, escolha profissional.

\section{Senior undergraduates: The influence of socio-economical and cultural variables in their career paths}

\begin{abstract}
In this paper we describe the profile of senior undergraduates attending courses in Chemistry, Biological Sciences and Psychology in a Brazilian public university. We propose to study the influence of socio-demographic and academic variables () on their career. The 140 participants answered a questionnaire on socio-demographic variables: parental education, family income, social-economical level and type of Elementary and High School (public or private) they attend. The academic variables (marks) were obtained from the university files. The data about career paths were obtained from interviews with six participants. The data were analyzed both quantitatively, according to unvaried models - the Square Q Test, the non-parametrical test: Kruskal-Wallis and Mann-Whitney and qualitatively, according to Bardin (1977). Both national and international theoretical frameworks underpinned the discussion. The study reveals that parental education, socio-economical level and type of Elementary and High School attended are directly related to their success in the university entrance tests and career choice.
\end{abstract}

Keywords: College students, professional development, occupational choice.

\section{Estudiantes universitarios: la influencia de las variables socio-económicas y culturales en la carrera}

\begin{abstract}
Resumen
Este estudio describe el perfil de egresados de los cursos de pre-grado: Química, Ciencias Biológicas y Psicología de una universidad pública y busca comprender influencias de las variables socio-demográficas y académicas en sus trayectorias de carrera. Los 140 participantes respondieron a un cuestionario con variables socio-demográficas: escolaridad de los padres, ingresos familiares, nivel socio-económico y procedencia de Enseñanza Primaria y Secundaria (pública o particular). Las variables académicas (notas) se obtuvieron en los archivos en la sección de pregrado. Las informaciones sobre las trayectorias de carrera (estudio de caso) se obtuvieron por medio de entrevistas con seis participantes. Los datos se analisaron cuantitativamente, según modelo univariado - Testes do Chi-Cuadrado, No-Paramétrico Kruskal-Wallis y de Mann-Whitney y cualitativamente según Bardin (1977). Referenciales teóricos nacionales e internacionales subsidiaron las discusiones. Se verificó que la escolaridad de los padres, nivel socio-económico y naturaleza de la enseñanza cursada están proporcionalmente relacionados al éxito en la prueba de ingreso de la universidad y a la elección de la carrera.
\end{abstract}

Palabras clave: Estudiantes universitarios, desarrollo profesional, escogimiento profesional.

Revista Semestral da Associação Brasileira de Psicologia Escolar e Educacional - SP, Volume 14, Número 1, Janeiro/Junho de $2010: 23-34$. 


\section{Introdução}

A problemática referente à qualidade do Ensino Fundamental, do Ensino Médio e do ingresso na Universidade é parte de um processo histórico que se iniciou com a colonização do Brasil. Por meio da análise da história da educação brasileira, da configuração do ensino público e privado e do acesso à universidade, pode-se compreender de que forma os desníveis nos setores educacionais se tornaram fruto da organização social, configurada por uma sociedade de classes (Romanelli, 1994).

A educação realizada na maioria das escolas públicas brasileiras tem carregado um estigma, uma marca de insuficiência quanto ao seu principal objetivo proposto: o ensino (Paro, 2000). Para o referido autor, o aumento no número de evasões e reprovações escolares, a escassez de professores, a indisciplina e a agressividade do aluno, o aligeiramento do ensino, entre outros, compõem o cenário precário em que se encontra o ensino público Fundamental e Médio. Assim, as representações sociais dos estudantes sobre o ensino público seguem o discurso da decadência da escola pública, datada há mais de três décadas. A representação negativa da escola pública encontra respaldo em pesquisas científicas que acompanham a trajetória decadente deste ensino há mais de 40 anos (Whitaker \& Onofre, 2006).

Por outro lado, na Educação Superior, frequentemente, as instituições públicas são consideradas de melhor qualidade, como se observa nos exames de ingresso. Uma vez que a relação candidato vaga é grande, são selecionados os candidatos melhor preparados para o tipo de prova que é realizada. Em decorrência disto, o cenário educacional brasileiro aponta o acesso ao Ensino Superior, nas carreiras de prestígio, como um mecanismo de manutenção das desigualdades sociais do país. Desta forma, o concurso vestibular se apresenta como barreira ritualizada porque não autoriza a passagem da esmagadora maioria que se submete a esse exame (Teixeira, 1981) e reflete as distorções e iniquidades da nossa sociedade (Pinho, 2001).

A fim de corrigir tais distorções, diversas alternativas para o ingresso no Ensino Superior foram e ainda estão sendo implementadas nos últimos anos, como processo seletivo, pontuação a partir do resultado do Exame Nacional do Ensino Médio (ENEM) e avaliação seriada, como apontam Melo-Silva, Lassance e Soares (2004), assim como programas de cotas universitárias, como política de ação afirmativa (Guarnieri, 2008; Guarnieri \& Melo-Silva, 2007).

Com todos os avanços ocorrendo nos meios de ingresso na carreira universitária, ela ainda não é, entretanto, acessível a uma grande parcela da população. As dificuldades de acesso remetem à Teoria da Reprodução Cultural de Pierre Bordieu em que se discute o conceito de violência simbólica (Bordieu,1998) como algo que permeia a divisão social de classes e as condições materiais e ideológicas em que repousam.

As escolhas profissionais inserem-se nessa trama simbólica e são objetos de interesse, sobretudo, do campo da Educação e da Psicologia. A escolha de uma carreira ou de um trabalho confere uma identidade social significativa para o indivíduo ao permitir que ele contribua produtivamente para a comunidade.

Como o planejamento de carreira deve ser combinado com o planejamento geral de vida, o aconselhamento deve dar o suporte necessário para o desenvolvimento de habilidades de planejamento de vida que instrumentalizem as pessoas para lidarem com as constantes mudanças sociais e situações individuais. (Savikas, 2000, citado por Jenschke, 2003, p. 40)

Swanson e Fouad (1999) enfatizam a importância do Orientador Escolar e Profissional apropriar-se do contexto cultural do estudante para estruturar o aconselhamento da carreira visto que os determinantes externos, como discriminação e pobreza, limitam o acesso à escolarização, afetando consequentemente as oportunidades de trabalho como também a percepção do cliente das mesmas. As autoras ressaltam a necessidade da compreensão da relação entre classe social e nível educacional e como estas forças, juntas, podem afetar as escolhas dos estudantes. Por sua vez, Niles e Harris-Bowlsbey (2005) apontam a escassez de modelos de desenvolvimento de carreira que abarquem as diferenças culturais, socio-históricas e econômicas. Desta forma, enfatizam a necessidade de desenvolver abordagens mais sensíveis a determinantes culturais.

Nesse sentido, analisando a Orientação Profissional brasileira, Ferretti (1992) afirma que a não superação da barreira no exame vestibular, por exemplo, torna-se motivo de culpa, principalmente para os jovens de classes subalternas que não conseguem desvendar as verdadeiras origens dos obstáculos que Ihes são antepostos. Isso acontece quando o sujeito não é visto a partir de seu contexto sócio-histórico como um todo e os determinantes sociais envolvidos na aprovação não são levados em consideração, deixando este peso exclusivamente às aptidões individuais do estudante. Nesse sentido, Bock e Aguiar (1995) defendem que a escolha ou não escolha profissional é parte de um processo dialético em que atuam muitos determinantes individuais e sociais os quais, assim, interferem nas trajetórias de carreira.

Importantes estudos sobre o Ensino Superior foram e estão sendo realizados a fim de ilustrar a dinâmica do cenário educacional brasileiro. O Núcleo de Pesquisas sobre o Ensino Superior (NUPES), em 2002, realizou um estudo acerca dos atributos socioeconômicos dos excluídos e dos ingressantes no exame vestibular da Universidade de São Paulo. Nesse estudo, foram analisadas, mais especificamente, as diferenças entre as carreiras no tocante às características sociais, educacionais e demográficas dos candidatos e quais seriam os fatores determinantes das possibilidades de aprovação no vestibular para cada grupo de carreira. O estudo confirma que há realmente um processo de autosseleção dos candidatos ao exame vestibular da Fundação Universitária para o Vestibular (FUVEST), que seleciona os candidatos que buscam a mais concorrida universidade brasileira, a Universidade de São Paulo (USP). E que o perfil dos aprovados é 
de jovens recém egressos do Ensino Fundamental e Médio privado, oriundos de famílias com alta renda e de cor branca. Independente da carreira escolhida, o sucesso no vestibular da USP associa-se basicamente à herança educacional e ao estudo em escolas particulares (NUPES, 2002). Tais resultados indicam a grande seletividade social no processo de ingresso. Em decorrência dessa situação, alterações no exame para ingresso na USP foram propostas no início de 1996, acentuando a discussão política (Da Silva, 2006).

A partir destas discussões, em 23 de maio de 2006 o Conselho Universitário aprovou a criação do Programa de Inclusão Social da USP (INCLUSP), que é composto por uma série de medidas destinadas a ampliar o acesso e a permanência na Universidade de alunos vindos de escolas públicas. Entre as mudanças, está o acréscimo de 3\% na pontuação obtida no vestibular da FUVEST para alunos que cursaram todo o Ensino Médio em escolas públicas. Tal mudança combina inclusão social com mérito acadêmico e a autonomia universitária, segundo a Reitora Suely Vilela (Jornal da USP, 2006). A meta é aumentar o percentual de alunos egressos do Ensino Médio público na universidade pública. A USP, por exemplo, tem realizado mudanças no exame vestibular e no INCLUSP. E o ENEM, depois de 10 anos de consolidação, passou a valer $20 \%$ do vestibular na USP e até $6 \%$ no INCLUSP' ${ }^{1}$. A fim de evitar a evasão, providenciam-se medidas como o estímulo à adoção de professor tutor, bolsas de moradia, de alimentação, de pesquisa e em atividades de cultura e extensão, por exemplo.

A associação entre os recursos educacionais e de renda familiar parece ser uma combinação recorrente manifestada pelos privilégios de quem pode estudar em uma escola particular (NUPES, 2002). Nesse sentido, toda e qualquer ação que visa democratizar mais o acesso à universidade é bem vinda.

Considerando a força do capital cultural da família como um influenciador de caminhos de seus filhos, independentemente das medidas tomadas pelas universidades, tal tema é e será pertinente em estudos que tratam do acesso e permanência na universidade e, por isso, será tratado no presente estudo. A noção de capital cultural emerge, primeiramente, segundo Bordieu e Passeron (1998), como uma hipótese que possa explicitar a desigualdade de desempenho escolar nas diferentes classes e também o modo como as especificidades da reprodução cultural operam dentro da escola. Esses autores correlacionaram uma série de fatores extraescolares (econômicos e culturais) que acabavam interferindo no desempenho e no aproveitamento estudantil.

Segundo Whitaker (1981), o capital cultural, além de agregar o capital ou a renda, agrega a história cultural daquele extrato social ao qual o indivíduo pertence. Seria um conjunto lógico e funcional de conhecimentos ligados à arte de um modo geral (literatura, teatro ou música), além da compreensão dos acontecimentos políticos (nacionais e

1 Palestra proferida por Selma Garrido Pimenta, Pró-Reitora e Graduação da USP em 15/06/09 na Universidade de São Paulo, campus de Ribeirão Preto internacionais), permitindo, por exemplo, alargar as possibilidades de se aprender História e Geografia. Livros, jornais e revistas, aliados a esse conjunto de conhecimentos transmitidos informalmente pelos adultos, adquirem funcionalidade na medida em que aquilo que o estudante lê tem muito a ver com aquilo sobre o que se conversa, dando a noção de continuidade. Isso leva à ampliação do vocabulário e à assimilação de uma sintaxe que ajuda a criar estruturas mentais adequadas aos conteúdos da escola, principalmente aqueles que são transmitidos em linguagem científica específica.

A disposição destes fatores culturais parece ter um peso igualmente importante na escolha da carreira e sucesso no vestibular, conforme verificado por meio de estudos realizados com os perfis de candidatos e aprovados da USP (NUPES, 2002), da UNICAMP (NUPES, 1997) e da UNESP (Fiamengue \& Whitaker, 1999), as três principais universidades públicas paulistas. Desta forma, os atributos socioeconômicos e o capital cultural podem dizer quais cursos, em termos de prestígio, condizem com tal extrato socioeconômico. A seleção já se inicia no ato da inscrição ao vestibular e na carreira escolhida, pois a distribuição dos candidatos por carreiras tem uma correlação com suas características sociais (NUPES, 2002).

Entretanto, existe uma pequena parcela de estudantes da rede pública de Ensino Médio que é aprovada nos exames vestibulares das mais concorridas carreiras em universidades públicas. Esses alunos superam as barreiras educacionais, sobrevivem ao ritual de passagem mencionado anteriormente e ainda conseguem concluir a graduação frente às adversidades da desigualdade de condições no acesso à universidade.

Existe demanda e existe acesso, mas há também o efeito gargalo que exclui a maioria dos candidatos desse nível de ensino. Segundo Petruccelli (2004), são dois os tipos de demanda: (a) a potencial, constituída por estudantes que concluíram o Ensino Médio e (b) a efetiva, que reúne os estudantes com maiores possibilidades de prosseguir os estudos na Educação Superior. Ainda de acordo com o referido autor, do total da população com idade superior a 17 anos, $81,4 \%$ (cerca de 88 milhões) não concluíram o Ensino Médio; e, dentre os $18 \%$ (20 milhões) que o concluíram, demanda potencial, apenas 2,8\% (3 milhões) cursam a universidade. Em termos etnicorraciais, o perfil da população que atingiu a universidade é assim distribuído: $79 \%$ se autodenominam de cor branca; $16,8 \%$, parda e 2,4\%, preta. Diante desse cenário, todas as medidas que visem à inclusão de mais jovens provenientes de diferentes condições sociais, na educação em todos os níveis, são relevantes. A inclusão e a permanência na universidade demandam estudos que possam gerar ações políticas para mudanças gradativas, efetivas e, ao mesmo tempo, urgentes.

Visando à ampliação da democratização do acesso à universidade, a Coordenação de Pesquisa da Comissão Permanente para os Vestibulares da Unicamp (COMVEST) investigou, no ano de 2003, quais seriam os aspectos da situação econômica dos candidatos ao vestibular da UNICAMP associados ao melhor desempenho acadêmico durante os 
cursos de graduação. Para tanto, o estudo foi realizado com alunos que ingressaram entre os anos de 1994 e 1997, totalizando 4.955 graduados. Os dados mostraram que os estudantes que cursaram o Ensino Médio em escola pública apresentaram desempenho superior ao longo do curso em relação aos provenientes do ensino privado. A interpretação fornecida pela COMVEST, para tal fenômeno, traz a possibilidade de que tais estudantes, por conseguirem superar muitas adversidades para chegar em igualdade de condições à universidade, têm potencial superior para se desenvolverem academicamente, se comparados aos estudantes dos outros grupos (COMVEST, 2004).

O referido estudo sugere que, em igualdade de condições, os estudantes egressos do Ensino Médio público teriam melhores desempenhos acadêmicos na universidade. No entanto, essa seria uma conclusão a ser estudada com cautela, pois, ainda assim, os aspectos democratizantes dentro da universidade podem despertar falsas interpretações, no sentido de que estes alunos, por estarem dentro de uma universidade pública, já são indivíduos privilegiados (NUPES, 1997).

Como se dá o desenvolvimento deste grupo de alunos durante a graduação numa universidade pública? Qual é o desempenho acadêmico do estudante universitário egresso do Ensino Médio público em comparação ao egresso do ensino particular? Quais as diferenças? Quais as semelhanças? A que se atribuem tais diferenças ou semelhanças?

O acesso à carreira universitária, assim como as formas de superação dos obstáculos, constituem objetos de interesse do campo da Orientação Profissional, enquanto teoria e prática. Assim sendo, este estudo insere-se no contexto de avaliação das problemáticas da Orientação Profissional e de Carreira. E é a partir dessa perspectiva que os dados foram coletados e analisados.

Para tanto, um estudo foi delineado com o objetivo de investigar o perfil acadêmico e sociodemográfico de estudantes universitários de três carreiras de uma universidade pública (Oliveira \& Melo-Silva, 2005), em função das variáveis: escolaridade dos pais, do nível socioeconômico e procedência do Ensino Médio (público ou privado). Este estudo objetiva, portanto, descrever o perfil de concluintes dos cursos de graduação Química, Ciências Biológicas e Psicologia de uma universidade pública e compreender a influência das variáveis sociodemográficas e acadêmicas em suas trajetórias de carreira.

\section{Percurso metodológico}

\section{Participantes}

A população deste estudo foi constituída pela totalidade de alunos graduados nos anos de 2003 e 2004 nas carreiras de Biologia, Psicologia e Química de uma universidade pública do interior paulista. O universo da população alvo deste estudo foi de 250 estudantes. Destes, 140 gradu- andos consentiram em participar deste estudo, subdivididos em três grupos de carreiras/curso. O curso de Química e o de Ciências Biológicas está representado por 41 estudantes cada um e o curso de Psicologia, por 59 estudantes. Os cursos de Biologia e Psicologia são de tempo integral e diurnos, enquanto o curso de Química é em regime parcial e no período noturno. No exame vestibular, são oferecidas 40 vagas para cada curso.

\section{Instrumentos}

\section{A coleta de dados foi realizada a partir de três principais instrumentos.}

1. Questionário. Este instrumento, elaborado pelas autoras, reúne informações sociodemográficas, tais como procedência escolar dos estudantes, escolaridade do pai, escolaridade da mãe e nível socioeconômico. A classificação para estimar o nível socioeconômico (NSE) dos participantes foi baseada na classificação da Associação Brasileira de Pesquisa de Mercado (ABIPEME). Novos itens de posse foram adicionados, tais como aparelho DVD, computador, fax doméstico, entre outros, e também informações sobre a situação de moradia (alugada, própria, entre outros).

2. Prontuários dos alunos. A partir dos prontuários arquivados na seção de graduação da universidade, foram extraídas as variáveis acadêmicas que compreendem as notas relativas ao exame vestibular (notas da $2^{\mathrm{a}}$. Fase) e as notas da Graduação.

3. Roteiro de entrevista. O Roteiro abordou dois eixos temáticos: (1) as trajetórias destes estudantes durante o Ensino Fundamental e Médio, (2) a trajetória universitária (o processo de ingresso e conclusão do curso) dos participantes.

\section{Procedimento de coleta}

Os dados foram obtidos em três etapas. Na primeira etapa, os alunos foram abordados em suas respectivas salas de aula objetivando obter o consentimento livre e esclarecido para a participação no estudo e as respostas ao questionário referido anteriormente. Para garantir maior adesão dos participantes, o questionário foi entregue aos alunos no ato da matrícula do último semestre da graduação. Na segunda etapa, conforme consentimento da Diretoria da instituição na qual o estudo foi realizado e dos estudantes, os prontuários foram acessados e os dados coletados. Para a terceira etapa, selecionou-se uma amostra de seis sujeitos - dois de cada curso, considerado neste estudo como carreira, sendo um proveniente de escola pública e outro de escola particular - para a realização de uma entrevista semiestruturada.

\section{Procedimento de análise dos dados}

A análise quantitativa foi feita por meio do tratamento estatístico dos dados coletados nas $1^{\text {a }}$ e $2^{a}$ etapas - informações sociodemográficas e acadêmicas. Para tanto, 
analisaram-se as variáveis coletadas a partir de um modelo univariado em dois conjuntos de análise: (1) Carreira (Química, Ciências Biológicas ou Psicologia) e (2) Nota (Notas da $2^{a}$. fase do vestibular e da graduação). Tais variáveis foram correlacionadas à escolaridade dos pais, ao nível socioeconômico e à natureza do ensino cursado.

No que se refere às notas da $2^{a}$. Fase do vestibular, optou-se por utilizá-las em detrimento das notas da $1^{\text {a }}$ fase (conforme NUPES, 2002), para obter um dado mais representativo do perfil do aluno ao se realizar a comparação entre notas do vestibular e graduação. Assim, a média das notas obtidas pela amostra de cada carreira foi ponderada a fim de se fazer uma análise comparativa das notas da graduação (pontuação 0-10) com as notas da segunda fase do vestibular (0-40). Cumpre destacar que a $2^{\mathrm{a}}$ fase contém disciplinas mais específicas da carreira e que constituem a base do conhecimento desenvolvido nas carreiras selecionadas para o presente estudo. Assim, as notas ponderadas da $2^{a}$ fase foram as das disciplinas básicas para o curso, como, por exemplo, a nota de Português para Psicologia, a nota de Biologia para Ciências Biológicas e a nota da disciplina Química para a carreira Química.

O desempenho acadêmico foi obtido a partir das médias da graduação dos estudantes, incluindo as reprovações e recuperações. O tratamento estatístico foi aplicado aos dados com a utilização de três testes principais: (1) o Teste do Qui-Quadrado $\left(\chi^{2}\right)$, adotado nível de significância $p$ $\leq$ 0,05, (2) o Teste Não-Paramétrico Kruskal-Wallis (ANOVA não-paramétrica), e (3) o Teste Não-Paramétrico de MannWhitney.

$\mathrm{Na}$ análise qualitativa, as entrevistas transcritas literalmente foram analisadas segundo a técnica de Análise de Conteúdo proposta por Bardin (1977). Realizou-se então uma análise do tipo Temático-Estrutural com a categorização dos temas emergentes, cujo procedimento foi a análise horizontal das entrevistas, objetivando compreender as interferências das variáveis nas trajetórias pessoais destes dois grupos de estudantes, a partir do referencial sócio-histórico brasileiro de Bock e Aguiar (1995) e das referências internacionais sobre as questões culturais e socioeconômicas de Swanson e Fouad (1999) e Niles e Harris-Bowlsbey (2005).

\section{Resultados e discussão}

\author{
Análise da Variável Carreira: Química, Biologia e \\ Psicologia
}

As informações sobre a escolaridade paterna e materna indicam que os cursos de Ciências Biológicas e Psicologia possuem percentuais significativamente diferentes em relação ao curso de Química, como mostra a Tabela 1. Nos dois primeiros, os maiores percentuais concentram-se no Ensino Superior (55\% e $61 \%$ para o pai e $43,9 \%$ e $64,9 \%$ para a mãe, respectivamente nos cursos), o que indica alta escolaridade, um dos importantes fatores para se avaliar o capital cultural dos estudantes. No entanto, na carreira de Química, os percentuais estão distribuídos com maior concentração no Ensino Médio (38,5\% para o pai e mãe).

Nota-se, portanto, que a carreira de Psicologia apresenta um perfil, para estas duas variáveis educacionais paternas, de maior escolaridade em comparação às outras duas carreiras. O inverso ocorre com a Química, carreira para a qual há sobrerrepresentação de candidatos cujos progenitores (pai e mãe) são menos escolarizados.

Em linhas gerais, focalizando a totalidade da amostra, evidencia-se que praticamente metade dos participantes possui pai $(50 \%)$ e mãe $(45,3 \%)$ com um alto nível de escolaridade, o que pode ser o primeiro indicativo da relação positiva entre altos níveis educacionais dos pais e sucesso no vestibular.

A variável nível socioeconômico (NSE) nos fornece a dimensão do status social dos estudantes. O NSE, conforme classificação da ABIPEME, é categorizado em A, B, C, D ou E. Neste estudo, foram considerados os níveis $A, B$ e $C$. O nível $C$ inclui o nível $D$, pois este não poderia ser analisado isoladamente, tendo em vista que o tamanho da amostra pertencente a este nível foi insuficiente para se trabalhar estatisticamente. Em relação ao nível $\mathrm{E}$, não houve nenhum estudante pertencente a esta classe, o que era esperado.

Desta forma, a Tabela 2 mostra que há diferença significativa entre o perfil dos cursos de Química e Psicologia no tocante ao nível socioeconômico, uma vez que, nestes, o percentual de alunos provenientes da classe A $(37,5 \%)$ é

Tabela 1. Distribuição em porcentagem dos participantes por carreira, em função da escolaridade do pai e da mãe

\begin{tabular}{lcccccc}
\hline \multirow{2}{*}{ Carreira } & \multicolumn{3}{c}{ Escolaridade do Pai ${ }^{*}$} & \multicolumn{3}{c}{ Escolaridade da Mã $\mathrm{e}^{* *}$} \\
\cline { 2 - 7 } & $1^{\circ}$ grau & $2^{\circ}$ grau & $3^{\circ}$ grau & $1^{\circ}$ grau & $2^{\circ}$ grau & $3^{\circ}$ grau \\
\cline { 2 - 7 } Química & $33,3 \%$ & $38,5 \%$ & $28,2 \%$ & $43,6 \%$ & $38,5 \%$ & $17,9 \%$ \\
Biologia & $20 \%$ & $25 \%$ & $55 \%$ & $14,6 \%$ & $41,5 \%$ & $43,9 \%$ \\
Psicologia & $5,1 \%$ & $33,9 \%$ & $61 \%$ & $8,8 \%$ & $26,3 \%$ & $64,9 \%$ \\
\hline Total & $17,4 \%$ & $32,3 \%$ & $50 \%$ & $20,4 \%$ & $34,3 \%$ & $45,3 \%$ \\
\hline$\chi^{2}=17,48 p=0,002^{*}$ & $\chi^{2}=27,88$ & $\mathrm{p}<0,001^{* *}$ & & &
\end{tabular}


Tabela 2. Distribuição em porcentagem dos participantes por carreira, em função do nível socioeconômico e natureza do Ensino Médio.

\begin{tabular}{lccccc}
\hline \multirow{2}{*}{ Carreira } & \multicolumn{3}{c}{ Nível Socioeconômico* } & \multicolumn{2}{c}{ Natureza do Ensino** } \\
\cline { 2 - 6 } & A & B & C & Público & Particular \\
\cline { 2 - 6 } Química & $12,3 \%$ & $66,7 \%$ & $21,1 \%$ & $22,5 \%$ & $77,5 \%$ \\
Biologia & $29,3 \%$ & $61 \%$ & $9,8 \%$ & $12,2 \%$ & $87,8 \%$ \\
Psicologia & $37,5 \%$ & $60 \%$ & $2,5 \%$ & $10,2 \%$ & $89,8 \%$ \\
\hline \multirow{2}{*}{ Total } & $24,6 \%$ & $63 \%$ & $12,3 \%$ & $14,3 \%$ & $85,7 \%$ \\
\hline$\chi^{2}=13,66 \quad p=0,008^{*}$ & $\chi^{2}=3,17 \quad p=0,21^{* *}$ & &
\end{tabular}

significativamente superior e, no curso de Química, há predomínio de estudantes provenientes da Classe C $(21,1 \%)$. Tais dados evidenciam que o nível social destes estudantes pode estar diretamente correlacionado à procura por determinada carreira universitária, conforme NUPES (2002).

Associando esta variável ao nível de escolaridade dos pais, pode-se afirmar que a carreira de Psicologia apresenta um perfil de recrutamento mais elitista e, por conseguinte, é tida como uma carreira de prestígio, enquanto a herança educacional dos alunos aprovados no curso de Química indica a menor elitização e prestígio deste curso. Ciências Biológicas, portanto, ocupa uma posição intermediária neste ranking. Tais dados confirmam o que a literatura apresenta: quanto maior o capital cultural dos pais dos aprovados, maior é o prestígio e a elitização do curso.

Apesar dos dados da Tabela 2 expressarem estatisticamente que não houve diferença significativa entre a natureza do ensino frequentado - se público ou privado - na comparação entre os cursos, observa-se uma tendência de que os estudantes provenientes do Ensino Médio público constituem maior número de alunos na carreira de Química $(22,5 \%)$, invertendo-se esta tendência para o curso de Psicologia $(10,2 \%)$. Desta forma, o tipo de escola (pública ou privada) frequentada pelos candidatos ao longo de sua história escolar parece influenciar de alguma forma no processo de escolha da carreira e da universidade. Cumpre destacar que a procedência escolar é uma das variáveis, em um contexto sócio-histórico mais amplo, que influencia tanto na escolha da carreira quanto nas possibilidades de ingresso e permanência na universidade. Segundo Bock e Aguiar (1996) e Ferreti (1992), as condições sócio-históricas influenciam de forma dialética: "A escolha profissional, como tantas outras na vida, expressa uma resposta possível, em um momento do indivíduo, resposta esta que se constitui e se organiza como um dos aspectos da subjetividade numa relação direta com o mundo objetivo" (Bock \& Aguiar, 1996, p. 21). Assim, aos alunos provenientes do Ensino Médio público, a carreira de Química da instituição em foco tornou-se uma possibilidade real de acesso a uma boa universidade.
Para Pinho (2001), o ingresso de alunos que cursaram integralmente seus estudos em escolas públicas é quatro vezes menor entre os inscritos para o vestibular em carreiras competitivas. O que leva alunos com menores vantagens sociodemográficas e acadêmicas a buscarem carreiras nas quais o nível de competição é menor? De acordo com o autor, "a escolha da carreira é feita de modo a aumentar a probabilidade de sucesso, mesmo que a vaga assim obtida não tenha um grande valor de mercado" (2001, p. 355), o que foi denominado "fase zero do vestibular".

Destaca-se também que o curso de Química diferencia-se dos outros por ser oferecido no período noturno, pelo qual muitas pessoas com nível socioeconômico menos favorecido optam em função da possibilidade de ter um trabalho no período diurno. Este aspecto também pode ser levado em consideração no processo de escolha.

Conforme os dados do NUPES (2002), observando as séries finais do Ensino Médio, pode-se perceber que a variável natureza do ensino tem influência no sucesso/insucesso do candidato. Como mostram os dados deste estudo, o Ensino Médio cursado em escola particular está sobrerrepresentado na amostra dos aprovados. Isso corrobora a associação principal entre procedência do ensino privado e aprovação no vestibular, notadamente porque, neste estudo, $85,7 \%$ dos participantes provêm do ensino privado e apenas $14,3 \%$ são egressos de escola pública.

\section{Análise das variáveis Notas da $2^{a}$ fase do vestibular e Notas da Graduação}

A partir da análise da variável escolaridade do pai, observou-se que as notas da $2^{a}$ fase do vestibular e da graduação dos filhos cujos pais possuem nível fundamental de escolaridade foram significativamente inferiores às notas dos filhos de pais que atingiram o Ensino Médio e Superior, que se equivaleram (segundo teste post hoc de Dunn), como mostra a Tabela 3.

Em relação à Escolaridade das mães, as notas da $2^{\mathrm{a}}$ fase do vestibular e da graduação dos estudantes cujas mães 
Tabela 3. Distribuição em porcentagem dos participantes em função da média das notas da $2^{\circ}$ fase e da Graduação e da escolaridade do pai e da mãe

\begin{tabular}{|c|c|c|c|c|c|c|}
\hline \multirow[t]{2}{*}{ Notas } & \multicolumn{3}{|c|}{ Escolaridade do $\mathrm{Pai}^{*}$} & \multicolumn{3}{|c|}{ Escolaridade da Mãe** } \\
\hline & $1^{\circ} \mathrm{grau}$ & $2^{\circ} \mathrm{grau}$ & $3^{\circ} \mathrm{grau}$ & $1^{\circ} \mathrm{grau}$ & $2^{\circ} \mathrm{grau}$ & $3^{\circ} \mathrm{grau}$ \\
\hline $2^{\circ}$ Fase $^{1}$ & 4,39 & 4,87 & 5,15 & 4,37 & 4,81 & 5,25 \\
\hline Graduação² & 7,14 & 7,85 & 7,81 & 7,42 & 7,52 & 7,95 \\
\hline $\begin{array}{l}k=10,86 p=0,004^{1} \\
k=10,53 p=0,005^{2}\end{array}$ & $\begin{array}{l}k=18,1 \\
k=8,87\end{array}$ & $\begin{array}{l}p<0,001^{1} \\
p=0,01^{2 * *}\end{array}$ & & & & \\
\hline
\end{tabular}

Tabela 4. Distribuição em porcentagem dos participantes em função da média das notas da $2^{a}$ fase do vestibular e da graduação e dos níveis socioeconômicos dos pais e a natureza do Ensino Médio.

\begin{tabular}{|c|c|c|c|c|c|}
\hline \multirow[t]{2}{*}{ Notas } & \multicolumn{3}{|c|}{ Nível Socioeconômico* } & \multicolumn{2}{|c|}{ Natureza do Ensino** } \\
\hline & A & B & C & Público & Particular \\
\hline $2^{\circ}$ Fase $^{1}$ & 5,20 & 5,01 & 4,57 & 4,48 & 5,00 \\
\hline Graduação $^{2}$ & 8,21 & 7,66 & 7,54 & 7,64 & 7,77 \\
\hline $\begin{array}{l}k=6,19 p=0,05^{1 *} \\
k=6,58 p=0,04^{2 *}\end{array}$ & $\begin{array}{l}Z=1,97 \\
Z=0,07\end{array}$ & & & & \\
\hline
\end{tabular}

completaram o Ensino Fundamental e Médio (conforme teste post hoc de Dunn) foram significativamente inferiores às dos filhos cujas mães atingiram o Ensino Superior.

A partir das correlações com a escolaridade do pai e da mãe, é possível perceber que o Ensino Superior, quando alcançado pelo pai e pela mãe, é o nível de escolaridade que mais interfere no desempenho dos estudantes. Tais resultados mostram claramente a relação diretamente proporcional entre a herança educacional dos pais e o desempenho dos filhos, uma vez que altos níveis de escolaridade dos pais parecem condizer com melhor desempenho escolar dos filhos. É interessante notar que a escolaridade dos pais ainda é uma variável de impacto na vida acadêmica do filho, sobretudo quando é baixa e inclusive em igualdade de condições de ensino.

No tocante ao nível socioeconômico dos pais, conforme a Tabela 4, as Notas da $2^{a}$ fase da FUVEST dos participantes cujas famílias possuem nível socioeconômico (NSE) $C$ foram significativamente inferiores às notas dos estudantes que possuem família com NSE A. O grupo de NSE B ficou numa posição intermediária e as notas dos participantes deste nível não foram significativamente superiores às do grupo $C$ ou significativamente inferiores às do grupo $A$ (a partir do teste post hoc de Dunn). Tais resultados confirmam mais uma vez que, quanto mais alto é o nível socioeconômico do candidato, maiores são as vantagens para o sucesso no vestibular.
A referida tabela também nos permite constatar que as notas da graduação dos estudantes de famílias com NSE $\mathrm{C}$ e $\mathrm{B}$ foram significativamente inferiores às notas dos participantes pertencentes ao grupo A. Ao correlacionar a variável NSE com a escolaridade dos pais, é possível dizer que o NSE A é um fator que pode discriminar o desempenho dos filhos, mesmo em igualdade de condições de ensino. Assim, o capital cultural é um fator que parece se perpetuar inclusive na graduação, influenciando no quesito desempenho acadêmico.

Em relação à procedência escolar no Ensino Médio, é possível verificar que as notas da $2^{\mathrm{a}}$ fase do exame vestibular dos alunos provenientes de escolas particulares foram significativamente superiores às dos estudantes egressos das públicas. Este dado nos permite constatar que há, sim, uma relação positiva entre capital cultural, procedência do Ensino Médio, desempenho no vestibular e acesso à universidade pois, uma vez que as notas são maiores para os que provêm do Ensino Médio privado, são maiores também as possibilidades de aprovação no vestibular. Assim, o desempenho médio dos alunos parece obedecer, predominantemente, a determinantes sociais e econômicos.

Além disso, é possível constatar que não houve diferença significativa entre o desempenho acadêmico - notas na graduação - dos alunos egressos de escolas públicas e particulares. Embora estudos da UNICAMP (COMVEST, 2004) constatassem que os egressos de escolas públicas 
superariam em notas os da escola particular, isto não se aplica ao presente estudo, que apresenta um número bastante reduzido de carreiras e de participantes. No entanto, em ambos os estudos (o da COMVEST e o presente estudo) pode-se afirmar que, em igualdade de condições de ensino, a procedência escolar é uma variável que parece não interferir negativamente no desempenho acadêmico dos participantes podendo, inclusive, afetá-lo positivamente, conforme estudo apresentado pela COMVEST.

Existe uma forte correlação entre escolaridade do pai e da mãe, nível socioeconômico e a procedência do Ensino Médio. A relação positiva configura-se da seguinte forma: os egressos do ensino público carregam uma herança de baixa escolaridade dos pais e suas famílias situam-se em níveis socioeconômicos inferiores. Seu desempenho no vestibular acaba também sendo mais baixo a partir das manifestações de insuficiência do ensino cursado e de capital cultural em relativa desvantagem em relação aos egressos do ensino particular e às exigências do vestibular e da educação superior. No entanto, na trajetória universitária, as notas da graduação não foram "afetadas" diretamente pela natureza do ensino cursado. Assim sendo, vale destacar que, além do capital cultural, é preciso considerar as inúmeras variáveis individuais (características pessoais como, por exemplo, traços de personalidade, interesses, aptidões, inteligência, autoeficácia, comportamentos proativos), mas, principalmente, outras variáveis contextuais, entre elas a necessidade de trabalho, o que pode decorrer em menor tempo de dedicação aos estudos. Mais investigações sobre o peso dessas variáveis na aprovação nos exames vestibulares e no sucesso acadêmico são necessárias.

Cumpre destacar que todos os cursos deste estudo apresentaram sinais de elitização visto que, para as três carreiras, a grande maioria dos estudantes é proveniente do ensino particular, comprovando o processo sócio-histórico em que a reprodução social garante a perpetuação do espaço de ação da classe dominante. Sendo assim, independente da elitização do curso, o estudante que ingressa na universidade pública já é um privilegiado se comparado ao conjunto da população brasileira.

Tabela 5. Distribuição em porcentagem dos participantes entrevistados $(n=6)$, em função do perfil sociodemográfico, educacional e acadêmico

\begin{tabular}{|c|c|c|c|c|c|c|c|c|c|}
\hline Sujeito & Carreira & $\begin{array}{l}\text { Natureza } \\
\text { Ensino }\end{array}$ & Idade & $\begin{array}{l}\text { Idade de } \\
\text { Ingresso }\end{array}$ & NSE & $\begin{array}{l}\text { Escolaridade } \\
\text { Pai/ Mãe }\end{array}$ & $\begin{array}{c}\text { Nota } \\
\text { vestibular }\end{array}$ & $\begin{array}{l}\text { Nota } \\
\text { grad. }\end{array}$ & $\begin{array}{c}\mathbf{N}^{\circ} \\
\text { Semestres }\end{array}$ \\
\hline 1 & QUI & PU & 24 & 18 & D & $\begin{array}{l}\text { Ensino } \\
\text { Fundamental } \\
\text { Incompleto }\end{array}$ & 4,2 & 6,6 & 13 de 8 \\
\hline 2 & $\mathrm{BIO}$ & PU & 28 & 23 & D & $\begin{array}{c}\text { Ensino } \\
\text { Fundamental } \\
\text { Incompleto }\end{array}$ & transferida & 7,9 & 8 de 8 \\
\hline 3 & PSI & PU & 27 & 23 & C & $\begin{array}{c}\text { Ensino } \\
\text { Fundamental } \\
\text { Completo }\end{array}$ & 5 & 7,9 & 11 de 10 \\
\hline 4 & QUI & PA & 22 & 18 & $A$ & $\begin{array}{l}\text { Ensino Médio } \\
\text { (pai) } \\
\text { Ensino } \\
\text { Superior (mãe) } \\
\text { Completos }\end{array}$ & 3,3 & 8,7 & 8 de 8 \\
\hline 5 & $\mathrm{BIO}$ & PA & 22 & 18 & B & $\begin{array}{c}\text { Ensino Superior } \\
\text { Completo }\end{array}$ & 5,2 & 7,3 & 8 de 8 \\
\hline 6 & PSI & PA & 23 & 18 & $A$ & $\begin{array}{c}\text { Ensino Superior } \\
\text { Completo }\end{array}$ & 4,9 & 8,5 & 10 de 10 \\
\hline
\end{tabular}




\section{Análise das entrevistas}

Com a análise das seis entrevistas realizadas, objetiva-se a discussão dos dados qualitativos em articulação com os resultados quantitativos. A Tabela 5 mostra o perfil sociodemográfico e acadêmico dos sujeitos entrevistados ( $\mathrm{n}$ = 6), confirmando em muitos aspectos a análise quantitativa realizada anteriormente. Pode-se verificar a diferença de nível socioeconômico e a escolaridade dos pais dos egressos de escolas públicas e particulares. O NSE dos egressos das "públicas" situa-se entre C e D e os de escola particular entre A e B. Pode-se observar também o ingresso tardio da maioria dos entrevistados egressos do Ensino Médio público na universidade e o prolongamento do tempo de graduação desses alunos. É preciso compreender, agora, os dinamismos e as subjetividades que envolvem tais questões.

A partir do relato dos participantes, é possível perceber a forma como os determinantes sociais interferem em sua trajetória educacional. Tais relatos permitiram verificar o impacto das variáveis sociodemográficas, educacionais e acadêmicas na vida dos dois perfis de estudantes.

As condições de ensino para os estudantes egressos do Ensino Médio público e privado foram contrastantes. Com as distinções relatadas, percebe-se a precariedade da qualidade de ensino para egressos de escolas públicas, de modo que, nos relatos, esta precariedade foi enfatizada no Ensino Médio, conforme as falas: "o colegial foi terrível, nós quase não tínhamos professores", "no meu caso, muitas aulas eram muito frouxas mesmo". Quanto aos egressos do ensino particular, os relatos foram de satisfação e qualidade pelo ensino: "eu observava a grande preocupação dos professores em você aprender".

Com o fim do Ensino Fundamental e Médio, os alunos estão submetidos aos graus - maiores ou menores - de liberdade da escolha, como aponta Ferretti (1992). O grau de liberdade destes participantes parece pautar-se nestas condições de ensino e no acesso aos bens culturais. Os egressos do ensino público trouxeram uma questão preliminar: cursar ou não cursar uma carreira universitária? As diferenças de condições principiam nas expectativas de metas e resultados. Algumas falas são representativas deste momento: "eu nunca imaginei na minha vida que eu pudesse fazer faculdade", "eu queria, mas não podia... uma faculdade que ficava como um sonho, lá, contido". Isto mostra como os graus de liberdade estão subjacentes a algo aquém do indivíduo, mas que muitas vezes o coloca numa posição falaciosa de sujeito livre para escolher. Pode-se questionar se de fato há livre arbítrio para quem está constrangido por condições sociais, econômicas e educacionais.

Assim, é possível perceber as restrições de escolha para os egressos do ensino público e as dificuldades com a preparação para o exame vestibular e o acesso ao Ensino Superior: "eu fiz um ano de cursinho... eu teria que aprender só coisas novas praticamente, algumas delas podiam ser um pouco mais familiares... todo o restante era muitíssimo novo, então era um trabalho colossal de se fazer", "eu conheci um cursinho popular, acho que chorei mais quando entrei no 'cursinho popular' do que quando eu entrei na faculdade". Os cursinhos denominados alternativos, populares e/ou comunitários objetivam preparar egressos do Ensino Médio público para o exame vestibular. Ingressar em um deles pode significar a superação de um primeiro obstáculo, o que auxiliará na superação dos demais.

Cumpre destacar que os determinantes sociais não são exclusivos, há que se considerar também os determinantes individuais, os atributos pessoais como, por exemplo, a autoeficácia percebida. No comportamento autoeficaz, as ações direcionam-se às ocupações que requerem as capacidades que o indivíduo pode ter ou desenvolver, estabelecendo metas e objetivos que persistem frente às barreiras surgidas na trajetória de sua realização, conforme observado nos relatos de alguns entrevistados.

Observando a trajetória destes dois perfis de alunos, é possível dizer que o perfil dos egressos da escola pública destaca-se em termos da apropriação cultural dos recursos que encontraram fora do âmbito escolar, conforme relatado: "além da escola e dentro dela... eu sempre li muito", "eu sempre fiz outras atividades... fazia balé clássico... fiz três anos de violão". Observa-se que tais alunos já são privilegiados ao poder entrar em contato com estes bens de capital cultural e, ao cursarem o Ensino Superior público, também ocupam um lugar privilegiado.

A questão é que, mesmo estando na graduação, que dispõe tais bens de capital cultural, estes parecem ser diferentes para os dois perfis de aluno. As adversidades enfrentadas pelos egressos do ensino público durante a graduação e o próprio nível econômico a que pertencem acabam interferindo no desempenho acadêmico: "a vinda pra cá foi muito difícil... o pessoal de casa não me ajudava na época, na verdade era o contrário, eu que ajudava em casa", "acho que eu entrei no esquema da faculdade aqui, não tive mais problemas", "então você já conhece os professores, você sabe o que tem que estudar... aí você consegue aproveitar um pouco mais, mas no início sempre é um pouco mais difícil".

Uma participante fez referência a um tema pertinente sobre a questão do apoio pedagógico ou psicopedagógico - orientações ou acompanhamento dos alunos que apresentam dificuldades acadêmicas e emocionais frente às condições de estudo. Ela diz: "não tive onde procurar apoio, muitos alunos que ingressam aqui ficam perdidos, não sabem onde procurar apoio". Essa fala aponta para a necessidade de serviços de apoio educacional e psicológico ao estudante, ou pelo menos de aumento na capacidade de atendimento em um serviço que existe no campus, porém com número insuficiente de vagas. Por outro lado, as verbalizações dos egressos do ensino particular sobre o ingresso à universidade fazem referência à satisfação e ao afeto: "eu achei tudo lindo, estava deslumbrada mesmo, em todos os aspectos"; "minha referência aqui são os meus amigos, e a nossa turma é uma turma que se uniu muito, então tudo que a gente fazia, a gente fazia junto".

Em contrapartida, é possível enumerar uma série de dificuldades enfrentadas pelos graduandos provenientes das escolas públicas: (a) necessidade de trabalhar, (b) necessi- 
dade de cumprir a carga horária de suas bolsas para poder se custear, (c) cuidar dos serviços domésticos, (d) enfrentar a fila da sala de computação destinada aos alunos para fazerem seus trabalhos (sendo que alguns computadores sempre estavam sem condições de uso), (e) restrição das fontes de pesquisa, pois os livros da biblioteca não são suficientes para atender à demanda e eles não têm dinheiro para comprar livros e, por fim, (f) os aspectos psicológicos envolvidos no enfrentamento destas adversidades.

A manutenção financeira foi um tema emergente, visto que nenhuma questão do roteiro das entrevistas abordava diretamente este assunto. Todos os egressos do Ensino Médio público disseram ter dificuldades para se manter financeiramente na faculdade: "eu também tive alguns problemas particulares, financeiros", "continuo dando aulas [de inglês], se não estivesse dando aulas eu não poderia ter vindo [referindo-se à cidade onde se situa a universidade]", "no último ano a bolsa acabou e aquele desespero que você tinha que se formar... sem trabalho, fazendo bico, então foi horrível, mas acabou".

Esta lista de aspectos adversos logicamente é amenizada ou não existe para muitos alunos que possam dispor deste capital cultural e econômico. Não se trata somente de uma distinção de natureza do ensino, visto que na análise quantitativa não houve diferença significativa entre o desempenho dos dois perfis de aluno; trata-se das condições materiais da universidade, das condições de tempo do aluno e das condições psicológicas para dispor de um capital cultural, enfim das condições mesmas de "transmissão" e apropriação deste capital cultural.

Ainda que os estudos da COMVEST (2004) tenham mostrado que os alunos egressos do Ensino Médio público obtiveram melhor desempenho acadêmico do que os egressos de escolas particulares, no caso do presente estudo as adversidades enfrentadas podem ser elucidativas sobre as diferenças encontradas nos dois estudos, mas não são suficientes para explicitar integralmente esta diferença. Pode-se afirmar que há muitas variáveis que interferem: a bagagem defasada em relação aos conhecimentos gerais no início da graduação, a falta de tempo decorrente das dificuldades financeiras para dedicação ao estudo, a falta de apoio psicopedagógico oferecido aos estudantes, entre outras dificuldades.

Estes estudantes tinham que trabalhar ou "fazer bicos" para sua manutenção e ainda a falta de recursos financeiros dificultava o acesso aos livros ou a equipamentos (computador, outros eletrônicos) que criam condições para os estudos. Para os estudantes em período integral, a administração do tempo era prejudicada. Em relação ao curso de Química, a própria dificuldade em relação à área de exatas foi um fator apontado.

Tais apontamentos sumarizam o efeito das interferências culturais e econômicas na vida dos dois grupos de estudantes. Niles e Harris-Bowlsbey (2005), no tocante às intervenções para o desenvolvimento de carreira, destacam a importância de se conhecer o contexto sociocultural dos clientes ou estudantes nesse caso, assim como capacitá-los a lidarem com tais diferenças. Inclusive sugerem a criação de programas universitários que promovam oportunidades experienciais, informações, orientação e atividades psicoeducativas. Nesse sentido, Swanson e Fouad (1999) referemse ao desenvolvimento de competências multiculturais do profissional para que se possa realizar um aconselhamento apropriado ao contexto cultural do estudante.

Entretanto, o fato da universidade não dispor de um serviço que se aproxime destas condições ideais soma-se às adversidades enfrentadas pelos estudantes, o que gera impacto no desempenho. Por fim, questiona-se qual deveria ser o perfil do profissional ideal para atuar no cenário apresentado, sobretudo no contexto brasileiro. Deve-se pensar em um profissional que atue na interface entre a Psicologia e a Educação tanto no Ensino Básico quanto no Superior e que seja consciente dos aspectos sócio-históricos, culturais e econômicos como fatores que interferem no comportamento do indivíduo.

\section{Considerações finais}

O mecanismo de reprodução social se apresenta sócio-historicamente instalado no Sistema Educacional brasileiro. A atual configuração deste sistema oculta o aspecto da historicidade desta reprodução e atribui ao sujeito a responsabilidade por sua posição social. A configuração do sistema público de Ensino Fundamental e Médio, dada por sua discriminação social a partir do sucateamento e aligeiramento do ensino, associa-se à configuração do ensino privado e suas relações mercadológicas. A despeito destas diversidades, o efeito cursinho tem aumentado e denunciado não só a qualidade do ensino nas duas naturezas de instituições de ensino - públicas e/ou privadas - bem como a incoerência das exigências do vestibular.

Estas configurações - positiva ou negativamente aumentam sobremaneira a seletividade social no processo de ingresso à universidade. No entanto, além da seletividade associar-se aos aspectos organizacionais do sistema educacional, ela está intimamente associada ao poder real e simbólico advindo do acesso aos bens culturais pelos indivíduos. Assim, o capital cultural está no cerne da reprodução social como uma categoria que separa e seleciona os ingressantes ao Ensino Superior, podendo predizer o grau de prestígio e elitização de uma carreira universitária, assim como interferir no próprio processo da escolha da carreira.

No Ensino Superior, a variável procedência escolar não influencia significativamente o desempenho acadêmico. Por outro lado, a força do capital cultural e das condições financeiras dos pais continua a interferir nas notas, no ingresso e na permanência do aluno na universidade.

A possibilidade de evasão do Ensino Superior a partir das dificuldades enfrentadas pelos egressos do ensino público mostra quão penosa se configura a alternação histórica. 0 peso da herança sócio-histórica que cada indivíduo carrega pode se expressar como aspectos favorecedores ou obstaculizadores das mediações e apropriações feitas no mundo circundante. Quando estes aspectos interferem negativamente 
nesse processo, a ação pessoal de luta contra a reprodução social não tem alcance suficiente. A ação coletiva, pensada e respaldada politicamente, exerce um alcance maior.

Isso remete aos questionamentos acerca da efetividade das políticas públicas de acesso à carreira universitária, sobretudo para aquela minoria ingressante com carência estrutural de recursos. E nisso a universidade passa a ter um papel muito importante no sentido de também se adequar às necessidades desse grupo de estudantes universitários e mesmo otimizar suas instalações, suas bolsas-auxílio, seu material de pesquisa. E, sobretudo, utilizar diferentes mecanismos de ingresso na universidade como o programa de cotas universitárias, entre outras alternativas, como apontado por Guarnieri (2008) e Guarnieri e Melo-Silva (2007).

O presente estudo contribui um pouco mais com a produção do conhecimento acerca do ingresso e desempenho acadêmico de alunos provenientes do Ensino Médio público. Nesse sentido, cumpre destacar a importância das medidas que estão sendo criadas e implementadas no país, seja em nível nacional, estadual ou municipal, por meio das políticas de ação afirmativas, como estratégias de enfrentamento aos problemas apontados pelos participantes em situação de constrangimento social, econômico e educacional por ocasião da coleta de dados desta pesquisa. Estudos sobre: (1) o processo de ingresso e permanência na universidade, (2) a avaliação das políticas de ação afirmativas e (3) o acompanhamento de universitários que ingressaram por meio de medidas de ação afirmativa são cada vez mais necessários. Atrair jovens de diferentes grupos sociais para as universidades significa ampliar a democracia e isto pode transformar o projeto de algumas famílias brasileiras, mas principalmente influenciar na definição de prioridades e na relação de poder nos centros de pesquisas. Um número cada vez maior de jovens na Universidade é necessário, tanto para atender às exigências do mercado de trabalho, que requer profissionais cada vez mais qualificados, quanto para que o País possa alcançar o desenvolvimento científico e tecnológico. Afinal, um país que possui o maior e mais diversificado sistema de ciência, tecnologia e inovação da América Latina, conforme apontam registros oficiais do Governo (http://www.brasil.gov.br/pais/ sobre_brasil), não pode ser um país com uma taxa baixa de estudantes universitários. Se a consolidação e a expansão do sistema nacional de ciência, tecnologia e inovação são estratégicas para o desenvolvimento soberano e sustentável do País e constituem metas para a diminuição da injustiça social, ampliar o número de jovens de diferentes condições sociais e econômicas ocupando as cadeiras universitárias é um dos caminhos para a verdadeira democracia

Finalizando, no âmbito institucional, tanto escolas do ensino básico quanto universidades devem investir em programas de intervenção na interface da Psicologia com a Educação - o Psicólogo Educacional e/ou Orientador Profissional, por exemplo - e que possam acompanhar o desenvolvimento da carreira de modo a aumentar a autoeficácia dos estudantes, bem como estimular comportamentos mais proativos e autônomos, tendo em vista a necessidade de enfrentamento das condições sociais, educacionais e econômicas e do estabelecimento de metas que visem às transformações necessárias para a construção de uma sociedade verdadeiramente democrática.

\section{Referências}

Bardin, L. (1977). Análise de Conteúdo. Lisboa: Edições 70.

Bock, A. M. B., \& Aguiar, W. M. J. (1995). Por uma prática promotora de saúde em orientação vocacional. Em A. M. B. Bock e cols., $A$ escolha profissional em questão. São Paulo: Casa do Psicólogo.

Bourdieu, P. (1998). Economia das Trocas Simbólicas. São Paulo: Perspectiva.

Bourdieu, P., \& Passeron, J. C. (1998). Escritos de Educação. Petrópolis, RJ: Vozes.

Comissão Permanente para os Vestibulares - COMVEST. (2004). Em Igualdade de Condições, alunos de graduação da Unicamp que estudaram na rede pública têm desempenho acadêmico superior. Campinas: Unicamp. Recuperado: 12 dez. 2004. Disponível: http:// www.comvest.unicamp.br/vest2004/desempenho_publica.pdf

Da Silva, J. A. (2006). Se alguma coisa existe, ela existe em certa quantidade e pode ser mensurada: o valor preditivo dos exames vestibulares. Revista Brasileira de Orientação Profissional, 7(1), 65-67.

Ferretti, C. J. (1992). Uma Nova Proposta de Orientação Profissional. São Paulo: Cortez.

Fiamengue, E. C., \& Whitaker, D. C. A. (1999). Dez anos depois: UNESP - Diferentes perfis de candidatos para diferentes cursos (estudo de varáveis de capital cultural). Pesquisa Vunesp, 11. Bauru: Fundação VUNESP.

Guarnieri, F. V. (2008). Cotas universitárias: perspectivas de estudantes em situação de vestibular. Dissertação de Mestrado, Universidade de São Paulo, Ribeirão Preto, São Paulo.

Guarnieri, F. V., \& Melo-Silva, L. L. (2007). Ações afirmativas na educação superior: rumos da discussão nos últimos anos. Revista Psicologia \& Sociedade, 19(2), 70-78.

Jenschke, B. (2003). A cooperação Internacional: desafios e necessidades da orientação e do aconselhamento em face das mudanças mundiais no trabalho e na sociedade. Revista Brasileira de Orientação Profissional, 4(1/2), 35-55.

Jornal da USP. (2006). Inclusão Social com mérito acadêmico. São Paulo: Jornal da USP, ano XX, $n^{\circ}$ 765. Recuperado: 02 ago. 2007. Disponível: http://www.usp.br/jorusp/arquivo/2006/jusp765/pag05.htm 
Melo-Silva, L. L., Lassance, M. C. P., \& Soares, D. H. P. (2004). A Orientação profissional brasileira no contexto da educação e trabalho. Revista Brasileira de Orientação Profissional, 5(2), 31-52.

Niles, S. G., \& Harris-Bowlsbey, J. (2005). Carrer Development Interventions in the $21^{\text {st }}$ Century. New Jersey: Pearson.

Núcleo de Pesquisas sobre o Ensino Superior - NUPES. (1997). Análise do perfil sócio-econômico-cultural dos ingressantes na UNICAMP (1987-1994): democratização ou elitização (documento 02). São Paulo: Universidade de São Paulo.

Núcleo de Pesquisas sobre o Ensino Superior - NUPES. (2002). Acesso à Universidade de São Paulo: Atributos socioeconômicos dos excluídos e dos ingressantes no exame vestibular (documento 03). São Paulo: Universidade de São Paulo.

Oliveira M., \& Melo-Silva, L. L. (2005). Egressos de Ensino Médio Público e Privado: Algumas trajetórias na carreira universitária. Relatório de Iniciação Científica do Programa de Bacharelado em Psicologia da Faculdade de Filosofia, Ciências e Letras da Universidade de São Paulo, Ribeirão Preto, São Paulo.

Paro, V. T. (2000). Por dentro da Escola Pública. São Paulo: Xamã.

Petruccelli, J. L. (2004). Mapa da cor no Ensino Superior brasileiro. Série Ensaios e Pesquisas. Laboratório de Políticas Públicas. Programa Políticas Públicas da Cor na Educação Brasileira, Universidade do Estado do Rio de Janeiro, Rio de Janeiro.
Pinho, A. G. (2001). Reflexões sobre o Papel do Concurso Vestibular para as Universidades Públicas. Estudos Avançados - Dossiê Educação, 15(42), 353-362.

Romanelli, O. O. (1994). História da Educação no Brasil. Petrópolis, RJ: Vozes.

Swanson, J. L., \& Fouad, N. A. (1999). Career Theory and practice: learning through case studies. London: Sage publications.

Teixeira, S. (1981). Vestibular: Ritual de Passagem ou Barreira Ritualizada? Ciência e Cultura, 33(12), 1574-1580.

Whitaker, D. C. A. (1981). A Seleção dos Privilegiados. São Paulo: Semente.

Whitaker, D. C., \& Onofre, S. A. (2006). Representações sociais em formação sobre os vestibulares dos estudantes de um cursinho comunitário na zona rural. Revista Brasileira de Orientação Profissional, 7(1), 45-55.

\section{Sobre as autoras}

Melina Del'Arco de Oliveira (melinadelarco@gmail.com)

Hospital das Clínicas da Faculdade de Medicina de Ribeirão Preto- Universidade de São Paulo, Ribeirão Preto - SP

Lucy Leal Melo Silva (lucileal@ffclrp.usp.br)

Faculdade de Filosofia, Ciências e Letras de Ribeirão Preta da Universidade de São Paulo, Ribeirão Preto - SP

\section{Correspondência}

\section{Lucy Leal Melo-Silva}

Departamento de Psicologia e Educação

Faculdade de Filosofia, Ciências e Letras de Ribeirão Preto- Universidade de São Paulo

Avenida Bandeirantes, $n^{\circ} 3900$

Ribeirão Preto - SP CEP: 14040-901 